Autism and fetal androgens: Commentary on Levy et al. (Lancet 2009; 374: 1627-38)

Martin Voracek

This manuscript version: November 20,2009

Martin Voracek, D.Sc., D.M.Sc., Ph.D., Department of Basic Psychological Research, School of Psychology, University of Vienna, Liebiggasse 5, Rm 03-46, A-1010 Vienna, Austria.

E-Mail: martin.voracek@univie.ac.at 


\section{Autism and fetal androgens: Commentary on Levy et al. (Lancet 2009; 374: 1627-38)}

The Seminar on autism by Susan Levy and colleagues ${ }^{1}$ is an excellent source of current knowledge on this neurodevelopmental disorder of prenatal and postnatal brain development and highly useful for generalists. The well-known sex difference in the lifetime prevalence of autism, wherein boys and men exceed girls and women by a large margin, along with its obvious prenatal origins, together suggest a role of prenatal factors wherein males differ from females in the aetiology of autism..$^{2}$

Prenatal androgens are one such early sexually differentiated factor. A now widely studied presumed retrospective biomarker for prenatal testosterone is the second-to-fourth digit ratio (2D:4D). ${ }^{3}$ Human 2D:4D is sexually differentiated (lower in males than in females), and sex and individual differences in 2D:4D emerge prenatally and are preserved during postnatal growth. ${ }^{3}$ Lower (male-typical) 2D:4D is associated with higher sensitivity to testosterone (i.e., functional polymorphisms in the androgen receptor gene) and a higher testosterone-to-estradiol ratio, as assayed from the amniotic fluid. ${ }^{3}$

Of note, children with autism or high-functioning autism (Asperger syndrome), as well as their unaffected first-degree relatives (siblings, mothers, and fathers), have conspicuously lower (hypermasculinised) 2D:4D than healthy general populations controls. ${ }^{4}$ This finding has been independently replicated in by now some ten further reports (reviewed elsewhere ${ }^{5}$ ). All in all, this points to a role of altered sex-hormone profiles, already arising in utero, in the pathways leading to the neurodevelopmental disorder autism. ${ }^{2}$ 


\section{References}

$1 \quad$ Levy SE, Mandell DS, Schultz RT. Autism. Lancet 2009; 374: 1627-38.

2 Baron-Cohen S, Knickmeyer RC, Belmonte MK. Sex differences in the brain: implications for explaning autism. Science 2005; 310: 819-23.

3 McIntyre $\mathrm{MH}$. The use of digit ratios as markers for perinatal androgen action. Reprod Biol Endocrinol 2006; 4: 10.

4 Manning JT, Baron-Cohen S, Wheelwright S, Sanders G. The 2nd to 4th digit ratio and autism. Dev Med Child Neurol 2001; 43: 160-4.

5 Voracek M. Digit ratio (2D:4D) as a marker for mental disorders: low (masculinized) 2D:4D in autism-spectrum disorders, high (feminized) 2D:4D in schizophrenic-spectrum disorders. Behav Brain Sci 2008; 31: 283-4. 